\title{
Erratum to: Infirmity and Injury Complexity are Risk Factors for Surgical-site Infection after Operative Fracture Care
}

\author{
Abdo Bachoura MD, Thierry G. Guitton MSc, \\ R. Malcolm Smith MD, Mark S. Vrahas MD, \\ David Zurakowski PhD, David Ring MD, PhD
}

Published online: 29 September 2011

(C) The Association of Bone and Joint Surgeons (R 2011

\section{Erratum to: Clin Orthop Relat Res (2011) 469:2621-2630 \\ DOI 10.1007/s11999-010-1737-2}

Due to a formatting error, in Table 8, the data for the second study by Minnema et al. were shifted to the right, thereby showing the data under the incorrect column headings. The table in correct format is shown below.

The online version of the original article can be found under doi: 10.1007/s11999-010-1737-2.

A. Bachoura, T. G. Guitton, D. Ring

Orthopaedic Hand and Upper Extremity Service, Massachusetts

General Hospital, Harvard Medical School, Boston, MA, USA

R. M. Smith, M. S. Vrahas

Department of Orthopaedics, Massachusetts General Hospital,

Harvard Medical School, Boston, MA, USA

D. Zurakowski

Departments of Anesthesia and Surgery, Children's Hospital

Boston, Harvard Medical School, Boston, MA, USA

D. Ring $(\varangle)$

Massachusetts General Hospital, Yawkey Center, Suite 2100,

55 Fruit Street, Boston, MA 02114, USA

e-mail: dring@partners.org 


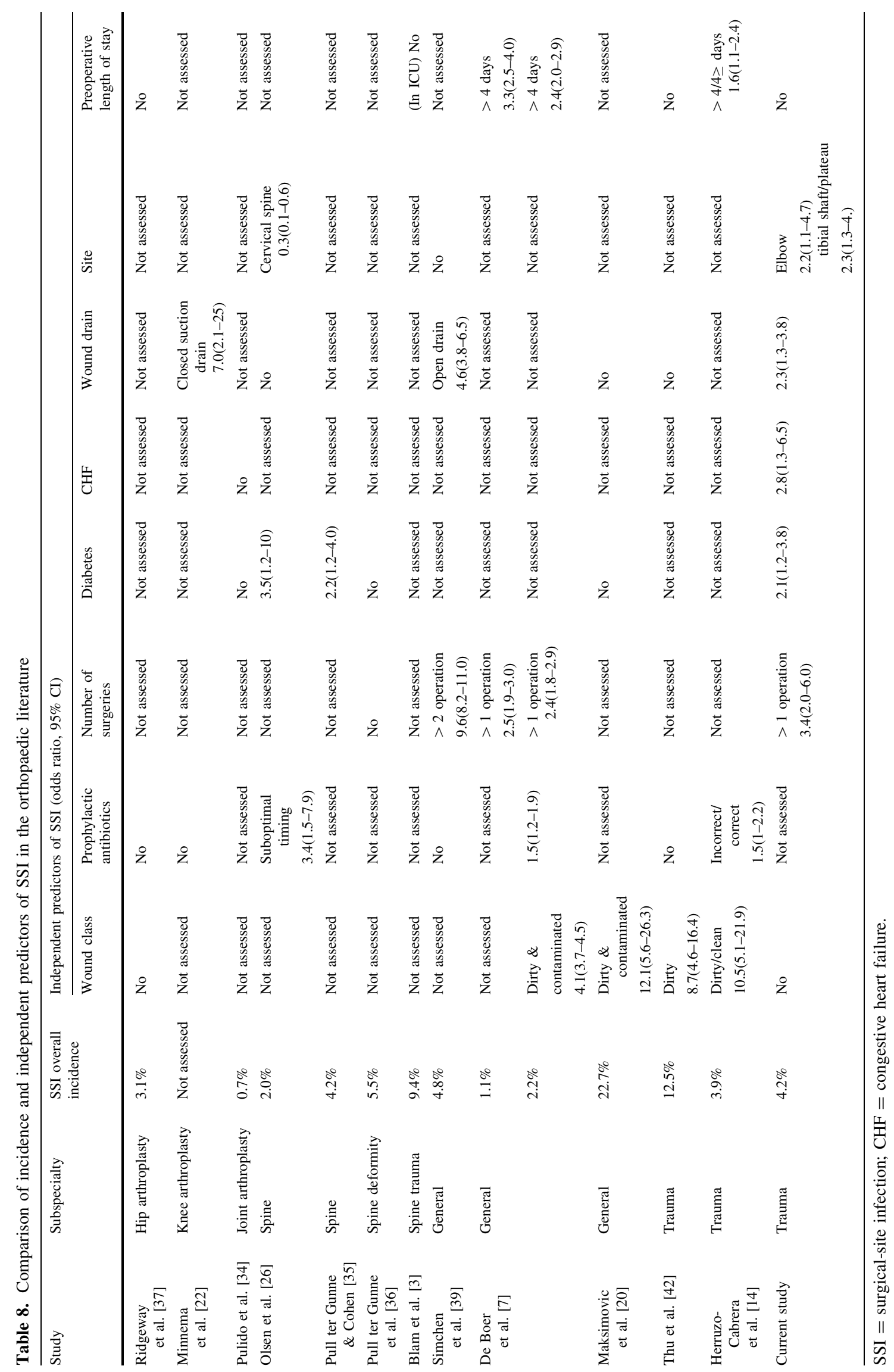

